Military Technical College

Kobry Elkobbah,

Cairo, Egypt

April 3-5,2018

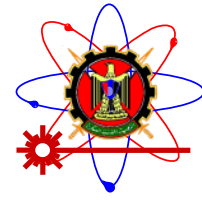

9th International Conference on Mathematics and

Engineering Physics (ICMEP-9)

\title{
The Design and Implementation of Under-Water Laser Imaging Test Aquarium
}

\author{
M. Darwiesh ${ }^{1}$, Ashraf F. El-Sherif ${ }^{2}$, HS Ayoub ${ }^{3}$, Yasser H. El-sharkawy ${ }^{4}$, and \\ Mahmoud F. Hassan ${ }^{5}$ \\ 1,2,5 Engineering Physics Department, Military Technical College, Cairo, Egypt. \\ ${ }^{4}$ Biomedical Engineering Department, Military Technical College, Cairo, Egypt. \\ ${ }^{3}$ Physics Department, Cairo University, Cairo, Egypt.
}

e-mail: M.darweesh@mtc.edu.eg

A test aquarium was built to perform and simulate different marine environment to optimize laser imaging of submerged targets. The setup enable to study the correlation between the detection angle, the target surface topology and color, water turbidity, and laser type at different depths and backgrounds. A theoretical model of the detection process was tested using MATLAB simulation. The system was able to simulate light extinction of the real deep and shallow aqua environments due to plankton chlorophyll as well as the effect of clay and mud water turbidity. The used dummy targets are approximately $1 / 500$ of the real submarines and naval mines. These targets were illuminated by several laser wavelengths in order to identify the targets with different color and shapes. The setup permits to test the efficiency of different target camouflage versus optical detection.

\section{Introduction:}

One of the biggest challenges in detecting underwater objects in hyperspectral imagery is that, unlike the landbased case, the observed spectrum of an underwater target is highly dependent on the properties of the surrounding water turbidity, as well as the depth of the target, and target camoflage.

Identifying pixels in any hyperspectral image that contain objects with a given reflectance spectrum - target detection - has been a very active area of research for a number of years [1]. While not always explicitly noted, most of the techniques that have been presented in the literature are landbased; in particular, they assume that the observed spectrum is independent of the water turbidity, detection angle, the target surface topology and color, and laser type at different depths and backgrounds (we assume here that all targets are full-pixel). 
Military Technical College

Kobry Elkobbah,

Cairo, Egypt

April 3-5,2018

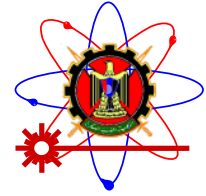

9th International Conference on Mathematics and

Engineering Physics (ICMEP-9)

Unfortunately, when the targets of interest are under water, this assumption is no longer valid. Since any light that reflects off the target and is captured by the sensor must first pass through the water column, it follows that the observed spectrum is highly dependent on the optical properties of the surrounding water. In other words, a given target will in general have very different observed spectra in different images. A consequence of this dependence is that the majority of existing detection algorithms are not directly applicable to underwater targets, and alternative methods are needed. By comparison to land, there have been only a few attempts to do so. Most of these approaches have been focused more on mapping particular bottom types [2], [3]. One of the only underwater target detection algorithms [4] in the literature attempts to modify existing land-based algorithms to the underwater situation.

\section{Theory:}

\subsection{Optical properties of water:}

As light propagates through water, light is absorbed and scattered in the water column. UV and IRlight are heavily attenuated in water. In clear ocean water, the deepest penetrating light is in the blue part of the spectrum with a maximum 1\% light depth of $\sim 300 \mathrm{~m}$, which is the depth where the light energy is $1 \%$ of the energy at the surface as shown in fig.1 in the demonstrating diagram. Compared with fjord waters, where the color is in the green part fig.2, maximum $1 \%$ light depth is $\sim 50 \mathrm{~m}[5,6]$.

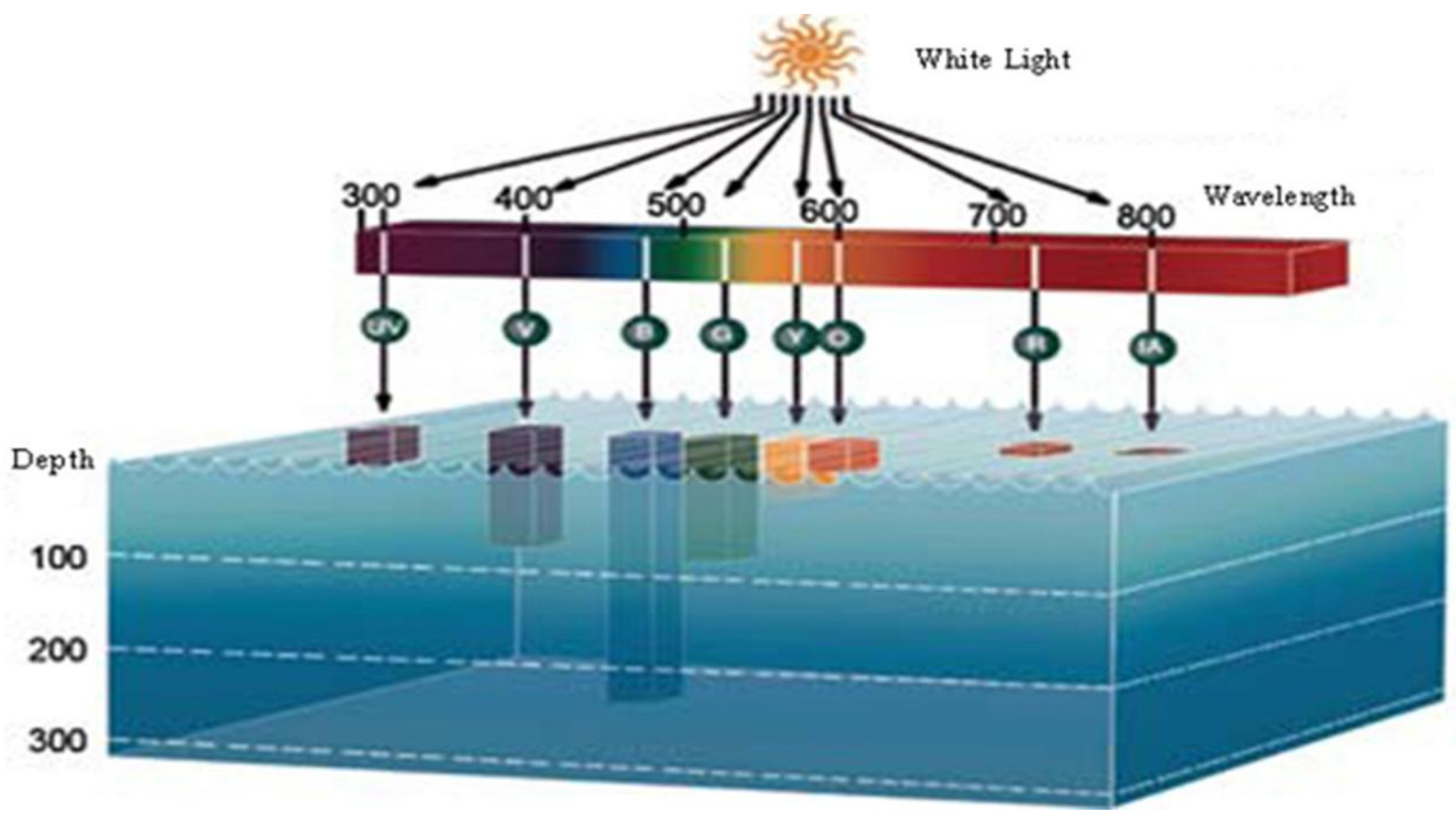


Military Technical College

Kobry Elkobbah,

Cairo, Egypt

April 3-5,2018

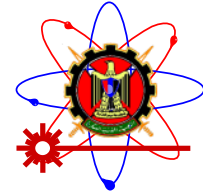

9th International Conference on Mathematics and

Engineering Physics (ICMEP-9)

Fig.1 the depth that light penetrates in clear ocean water.
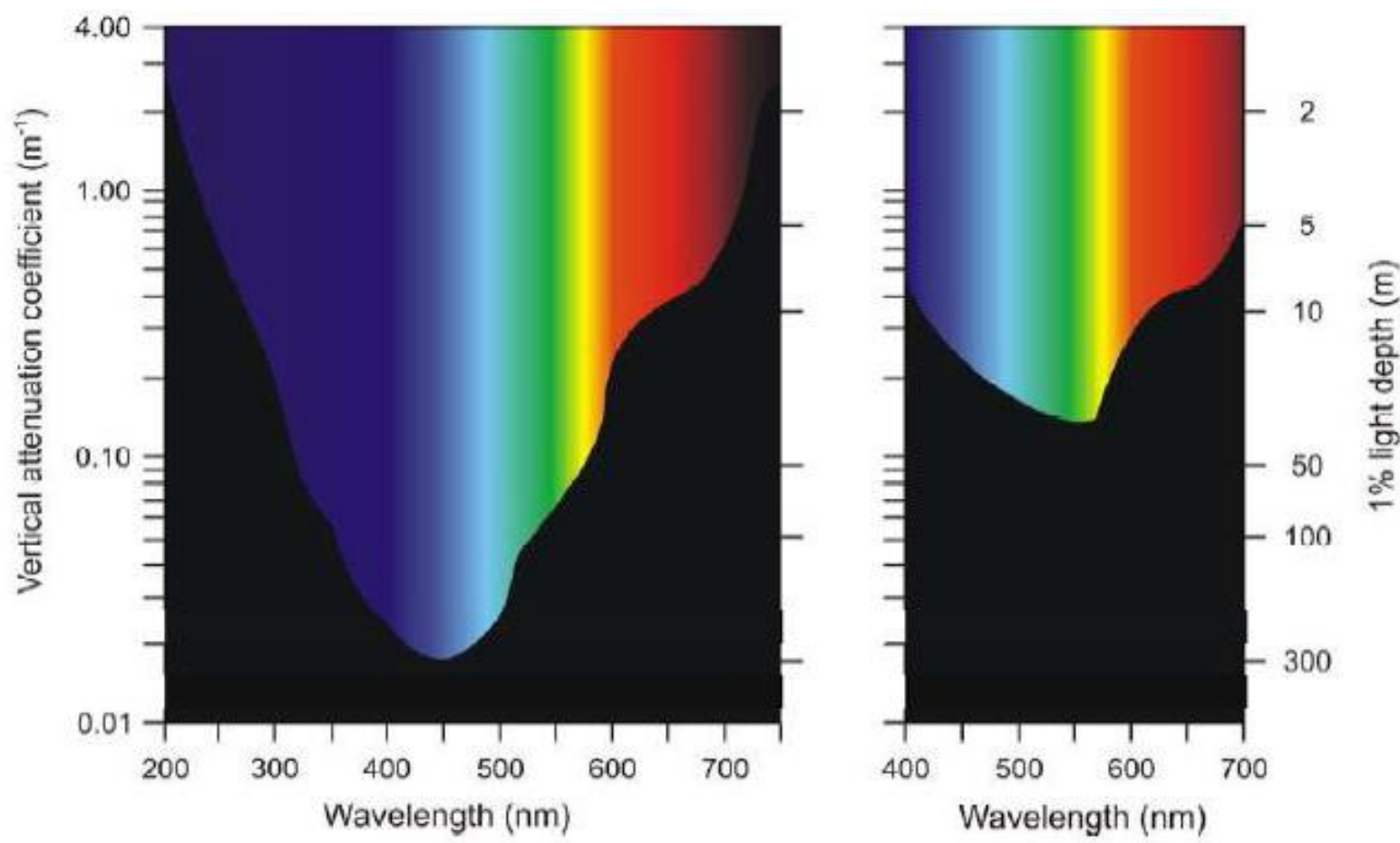

Fig.2 In blue ocean water (to the left), the color is blue because the deepest penetrating wavelength is approx. $450 \mathrm{~nm}$. Fjord water (to the right), has a green color where the deepest penetrating wavelength is approx. 550nm

Substances in water affecting its optical properties are water molecules, phytoplankton, colored dissolved organic matter (CDOM) and total suspended matter (TSM). Water molecules absorb in the blue part of the spectrum and scatter in the red part of the spectrum. Phytoplankton are living organisms using light for photosynthesis. The main pigment in phytoplankton absorbing photons is chlorophyll a (Chl $a)$. It absorbs photons highest in the green $(440 \mathrm{~nm})$ and the red $(675 \mathrm{~nm})$ part of the spectrum. CDOM originate from the decomposition of organic material (plant and planktonic tissue) and is only absorbing, not scattering. It has a maximum absorbance in the UV and blue part of the spectrum. TSM can be separated into particulate organic material (POM) and particulate inorganic material (PIM) [7]. Due to the intense scattering from TSM, absorbance is difficult to measure. However, absorbance of PIM has been measured to be high in the red end of the 
Military Technical College

Kobry Elkobbah,

Cairo, Egypt

April 3-5,2018

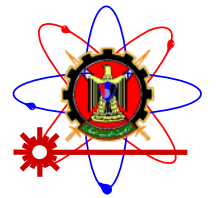

9th International Conference on Mathematics and

Engineering Physics (ICMEP-9)

spectrum, gently decreasing with increasing wavelength [8]. The absorption spectra of suspended substances are shown in fig.3.

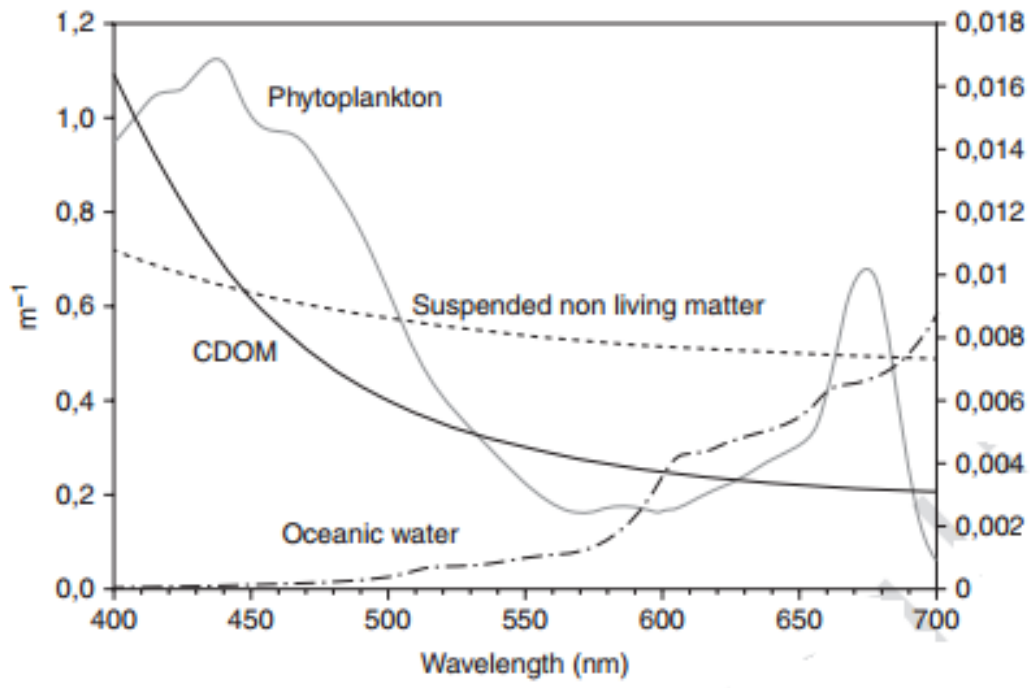

Fig.3 The absorption spectra of phytoplankton, CDOM, oceanic water and suspended non-living material

\section{2 hyperspectral remote sensing}

The spectral resolution of the human eye is limited to three wavelengths, red ( $600 \mathrm{~nm})$, green $(\sim 550 \mathrm{~nm})$ and blue $(\sim 450 \mathrm{~nm})$, giving us a trichromatic perception of colors (RGB-vision).

Television, cameras and other artificial digital image displays and sensing systems normally use "pseudo-true" colors in RGB images, with bands centered at $450 \mathrm{~nm}, 550 \mathrm{~nm}$ and $650 \mathrm{~nm}$. A multispectral imager, used for remote sensing from satellites, captures more than three wave bands. Typically, it uses 10-20 bands in the ultraviolet, visible and near-infrared part of the electromagnetic spectrum. Multispectral (>5 nm wavebands) and hyperspectral imaging are based on the same principles, but the HI has a better spectral resolution than the multispectral, providing wavelengths with $1 \mathrm{~nm}$ spectral resolution [8].

A hyperspectral imager is a spectrometer equipped with a camera. The spectrometer separates reflected solar energy from the surface into spectral bands, which are narrow wavelength intervals [9]. The senor used for the camera is a charge coupled device sensor roducing images of the target consisting of pixels with different optical properties.

Images are captured through an entrance slit and are reconstructed into an image of the entire area of interest with high spectral and spatial resolution, by merging the spectral profiles into an image cube fig.4. This is called the "push-broom technique" [10]. 
Military Technical College

Kobry Elkobbah,

Cairo, Egypt

April 3-5,2018

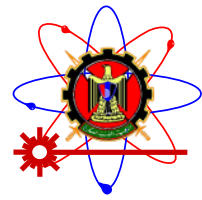

9th International Conference on Mathematics and

Engineering Physics (ICMEP-9)

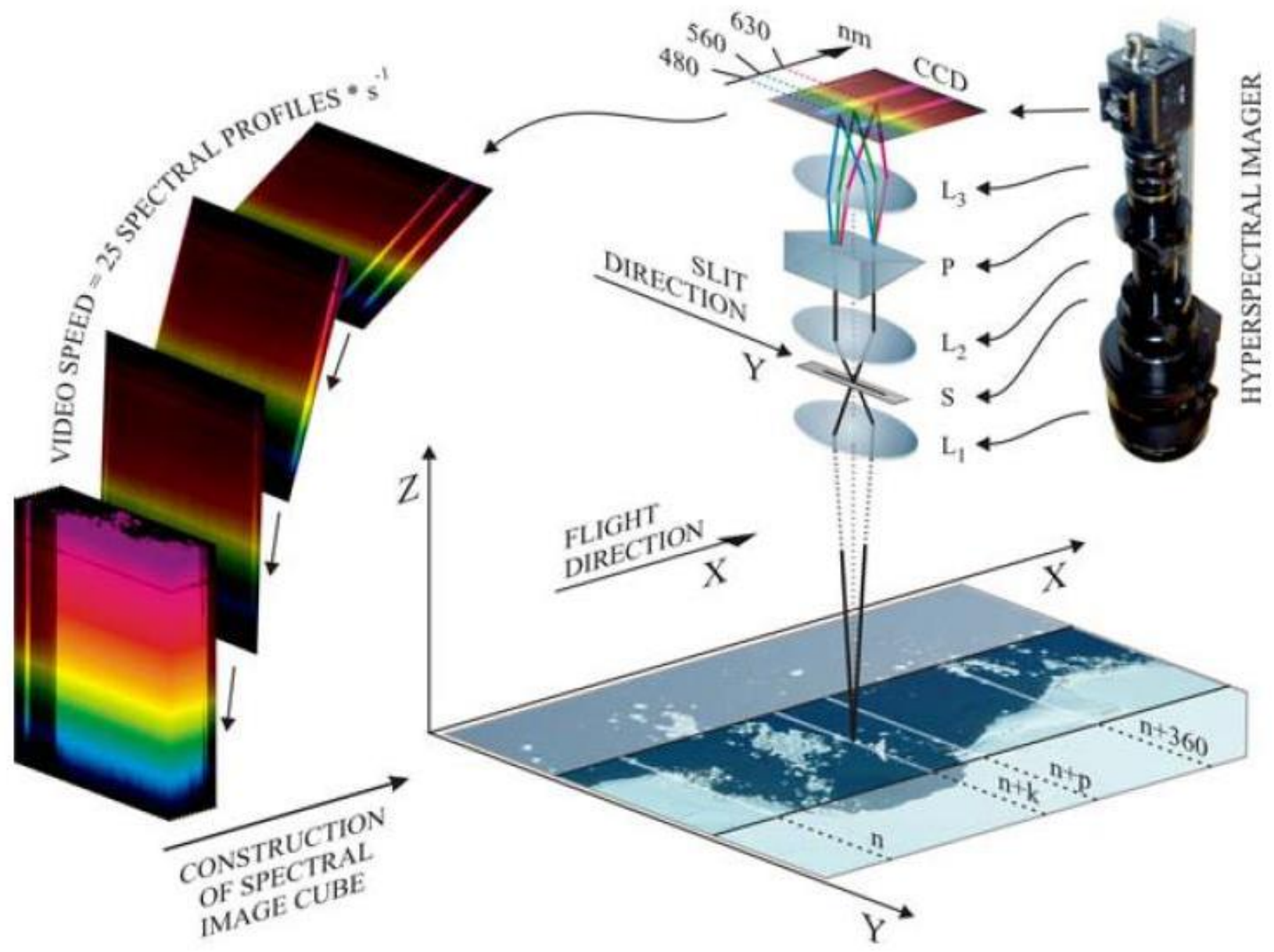

Fig.4 Model illustrating the hyperspectral imager, the "push broom" technique and the spectral image cube. $L 1=$ front lens, $S=$ entrance slit, $L 2=$ collector lens, $P=$ prism, $L 3=$ camera lens and $C C D=$ imaging detector (Charged Coupled Device), $n=$ amount of pixels in $X$-direction.

A hyperspectral image provides a full reflectance spectrum per image pixel. The reflectance spectrum shows the reflectance per wavelength (1 nm resolution). Spectral features are observed as peaks and drops in the spectrum and determine the optical signature (shape of the spectrum), which can be obtained from a pixel and used to classify the objects in the pixel [7]. In addition, the intensity of the optical signature can be used to separate objects. By using the optical signatures of objects on the seabed it is possible to identify and map the biogeochemical patterns of interest. Monochromatic images can be extracted from the image cube fig.5. These images show the upwelling radiance intensity of the selected wavelength and intensities are given in $\mathrm{mWm}^{-2} \mathrm{~nm}^{-1}$ [8]. 
Military Technical College

Kobry Elkobbah,

Cairo, Egypt

April 3-5,2018

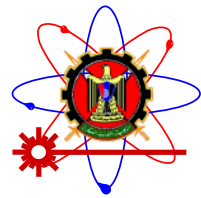

9th International Conference on Mathematics and

Engineering Physics (ICMEP-9)

Pettersen [11,12] describes two methods of classifying objects based on optical signature. A supervised classification of a hyperspectral image can be accomplished by choosing classes based on optical signature and use these to classify pixels in the image. Statistical software is used for the classification. An unsupervised classification is done without predefined classes. This classification is also accomplished by statistical software where pixels are classified based on differences in radiation and reflectance.
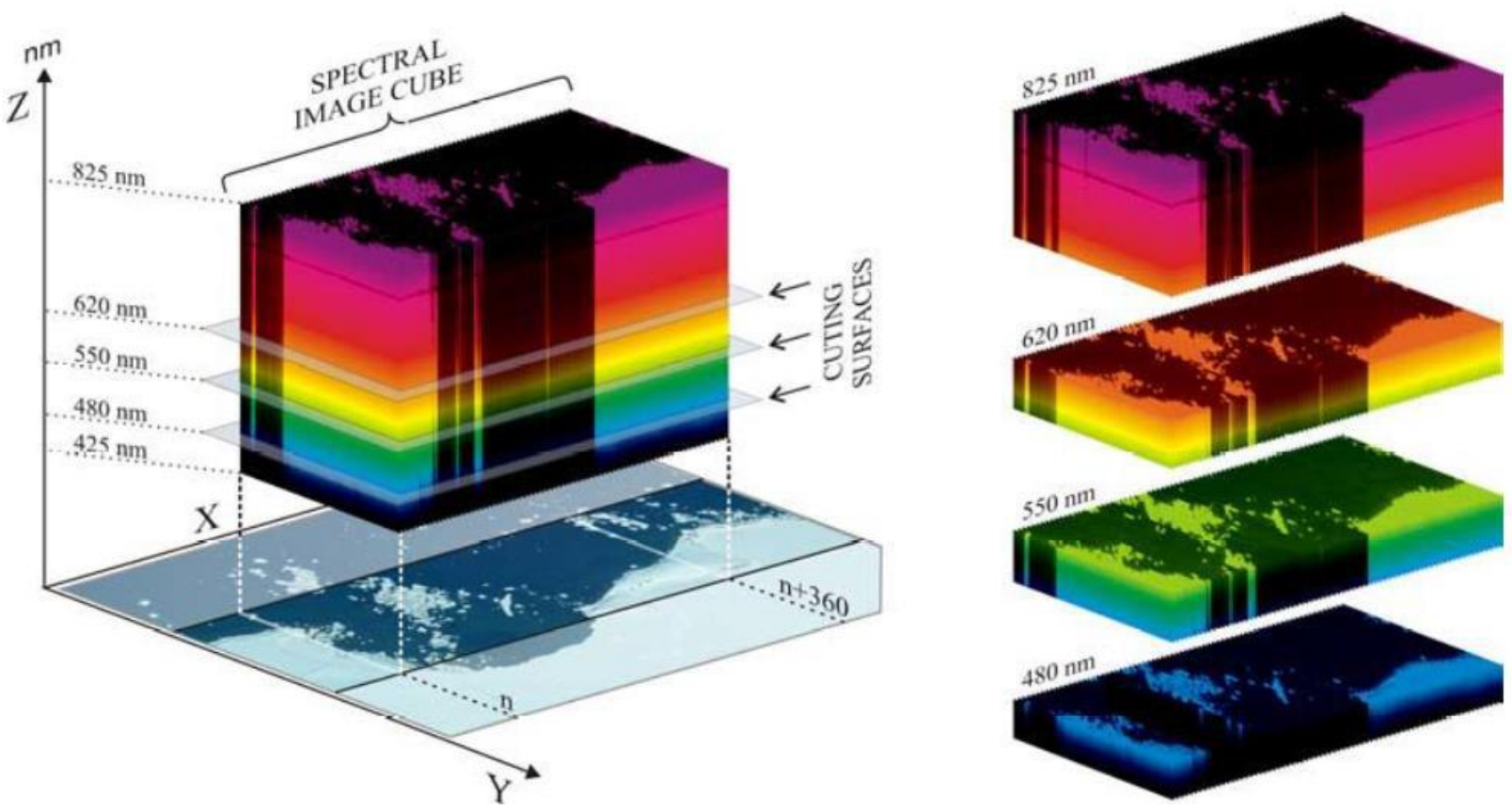

Fig.5 The method of choosing monochromatic images from the spectral image cube to make specific identification images. At the cutting surfaces, the pixels of horizontal planes show reflection intensities at one specific wavelength

\section{Simulation Model:}

A MATLAB model for submerged target detection is presented which allows the user to identify and localize the presence of underwater targets which have measurable light reflectance. The main idea of the program is to simulate and collect the different powers received from different round trip times at different scanning rays whose number is determined based on the resolution of scanning of the working area. Absorption, scattering, and backscattering of light in different media through which light propagates were taken into consideration to achieve the accurate values of the received power from different target shapes which expresses the real conditions. Once the target is detected, the reflected power is from the outer surface facing the laser source only, then there is no power reaching the inside of the target nor the region beyond the target (target shadow) and the reflected power from that shadow area is equal to zero [13]. 
Military Technical College

Kobry Elkobbah,

Cairo, Egypt

April 3-5,2018

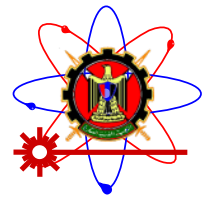

9th International Conference on Mathematics and

Engineering Physics (ICMEP-9)

Fig.6 shows the output from the simulation where Fig.6-a represents the scattering distribution vs. depth and Fig.6-b represents the absorption distribution vs. depth and Fig.6-c represents the backscattering distribution from all particles in the working area vs. depth and Fig.6-d represents the backscattering distribution in the presence of target vs. depth and Fig.6-e represents the scattering distribution in the presence of target vs. depth and Fig.6-f represents the total attenuation distribution in the presence of target vs. depth and Fig.6-g represents the received power distribution from different round trip times at different scanning rays.

What appears in Fig.6-g as a wall is the reflected power from the water surface. The spikes that appear in the middle are the reflected power from the target surface, which has a much larger value than the surrounding water constituents. A region with zero reflected power appears behind the target, this is the shadow of the target which returns zero power as laser signals are blocked by the target body.

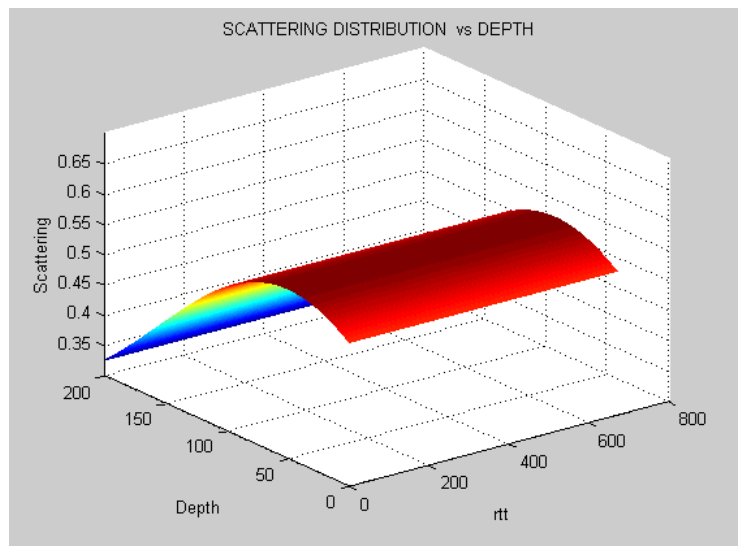

(a)

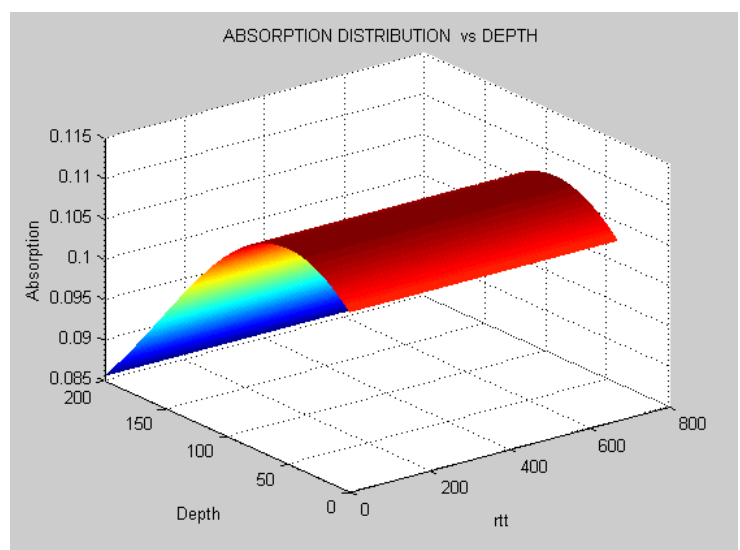

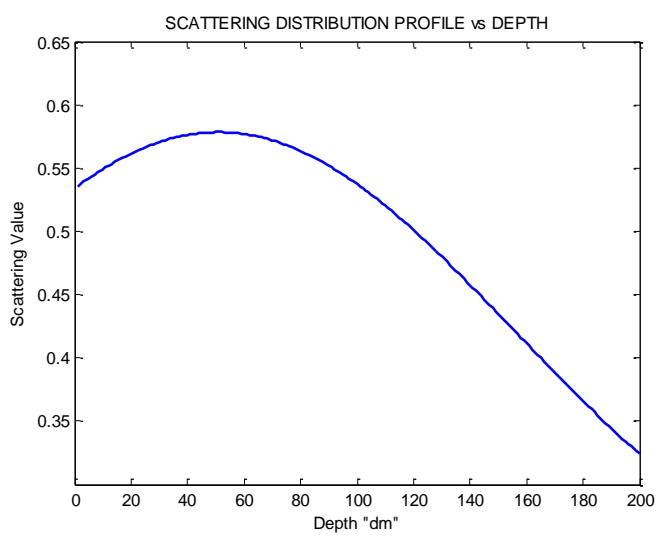

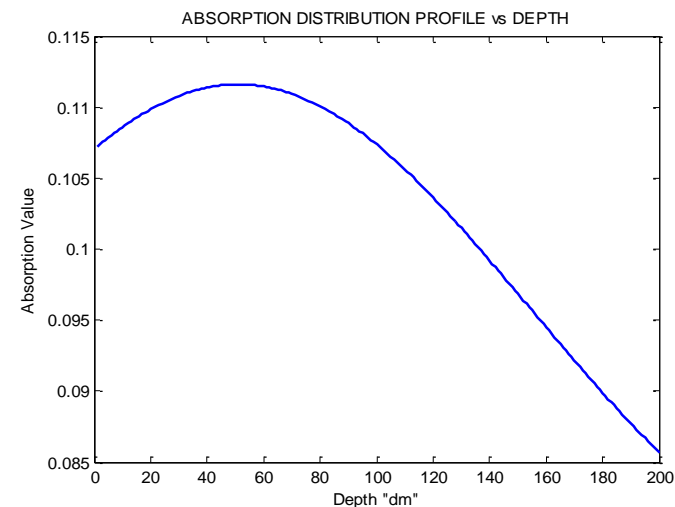


Military Technical College

Kobry Elkobbah,

Cairo, Egypt

April 3-5,2018

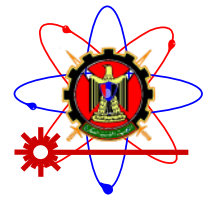

9th International Conference on Mathematics and

Engineering Physics (ICMEP-9)
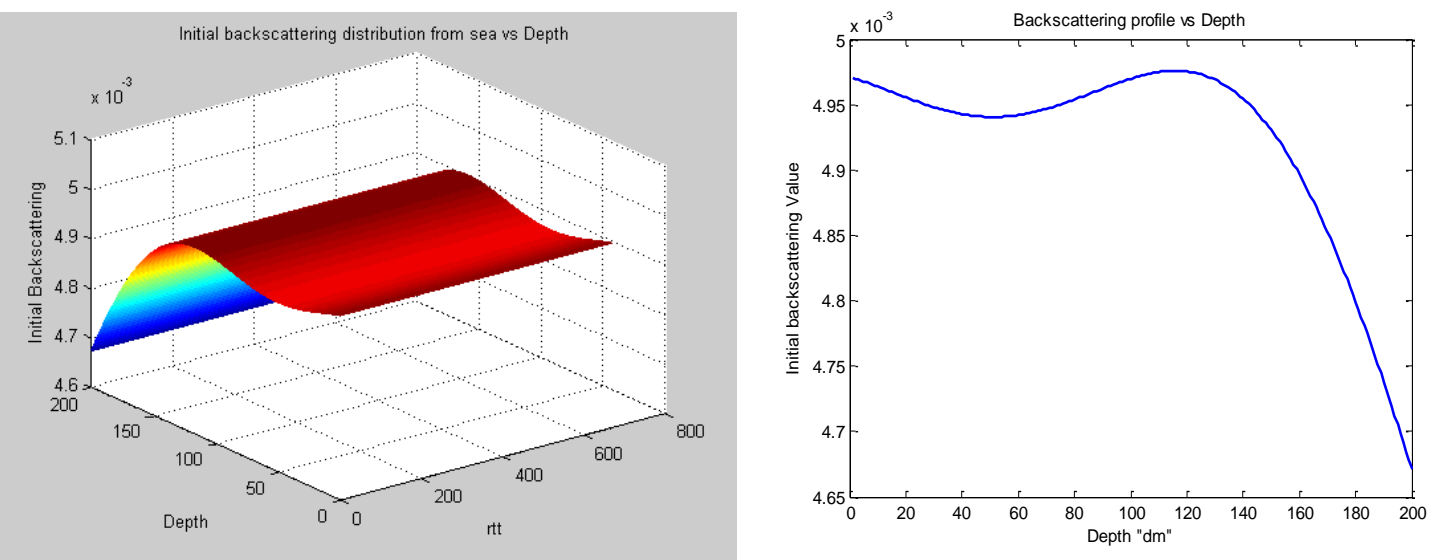

(c)

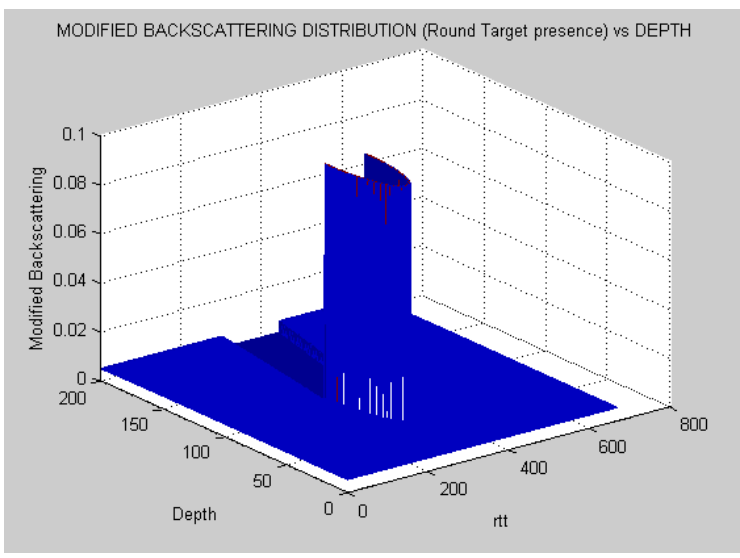

(d)

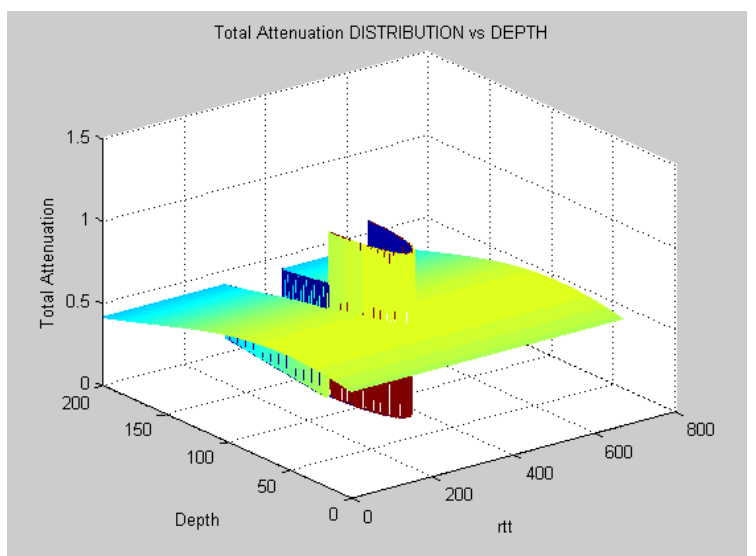

(f)

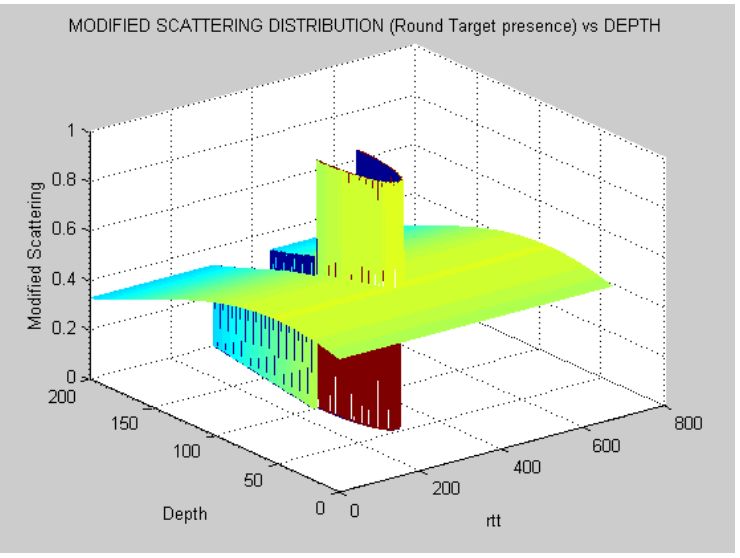

(e)

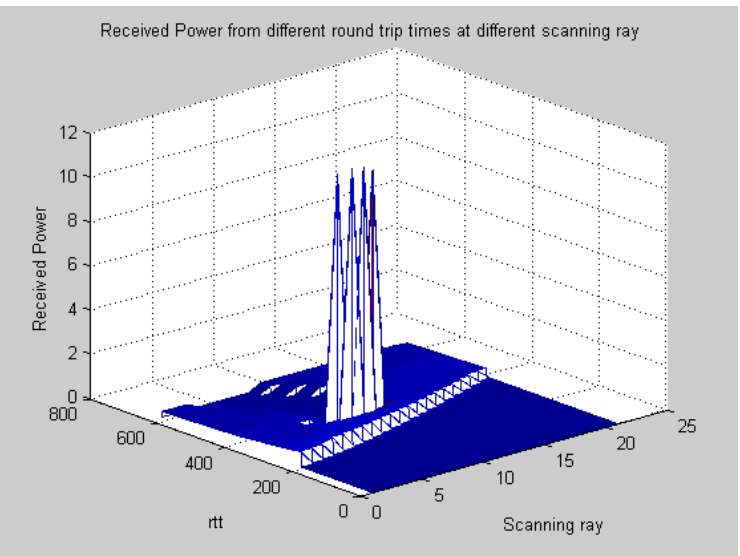

(g) 
Military Technical College

Kobry Elkobbah,

Cairo, Egypt

April 3-5,2018

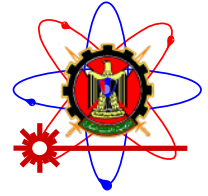

9th International Conference on Mathematics and Engineering Physics (ICMEP-9)

Fig. 6. simulation output (a) represents the scattering distribution vs. depth, (b) represents the absorption distribution vs. depth, (c) represents the backscattering distribution from all particles in the working area vs. depth, (d) represents the backscattering distribution in the presence of target vs. depth, (e) represents the scattering distribution in the presence of target vs. depth, $(f)$ represents the total attenuation distribution in the presence of target $v$ s. depth, and (g) represents the received power from different round trip times at different scanning ray.

\section{Experimental Setup:}

Fig.7 illustrates the experimental setup which simulates the sea environment. The experimental setup consists of test aquarium, Argon laser, hyperspectral camera, pigmented saline water and different shapes of camouflaged targets.

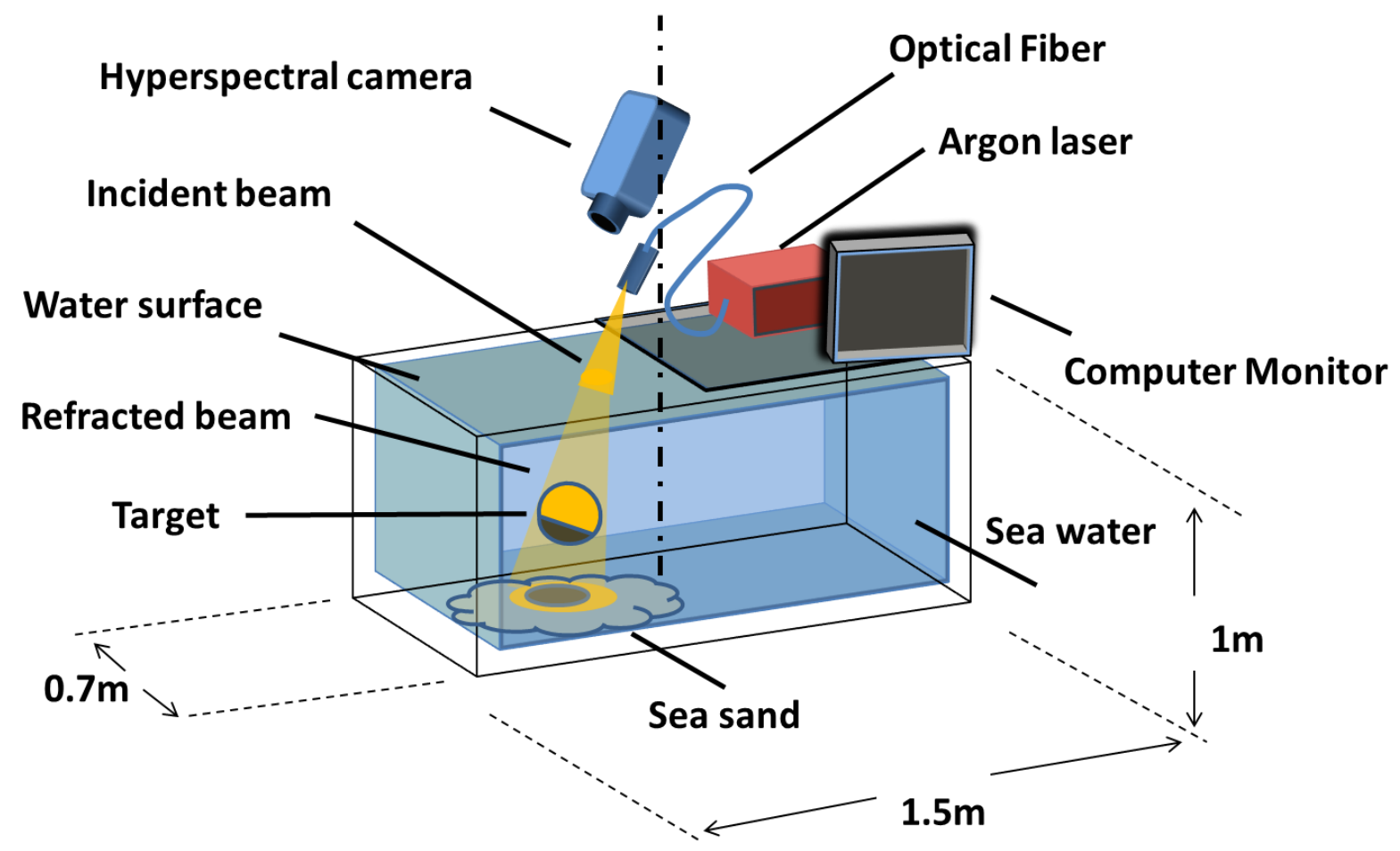

Fig.7 Experimental setup diagram 


\section{Military Technical College \\ Kobry Elkobbah, \\ Cairo, Egypt \\ April 3-5,2018}

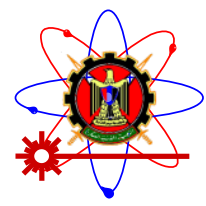

\section{9th International Conference on Mathematics and \\ Engineering Physics (ICMEP-9)}

The test aquarium is designed as shown in fig.7 with dimension $\left(1.5 \mathrm{~m}^{*} 0.7 \mathrm{~m} * 1 \mathrm{~m}\right)$ and with transparent glass walls to helps us to fulfill the sea environment in the laboratory scale and to be able to follow the underwater camouflaged targets under different water conditions.

The targets were illuminated by Argon laser with multiple output wavelengths (457nm -488nm $514 \mathrm{~nm}$ ) is used in our experimental work because these wavelengths in the blue and green bands which have less attenuation and deepest penetrating in water. Fig.8 shows a clear photo for the experimental setup in the off- laser mode.

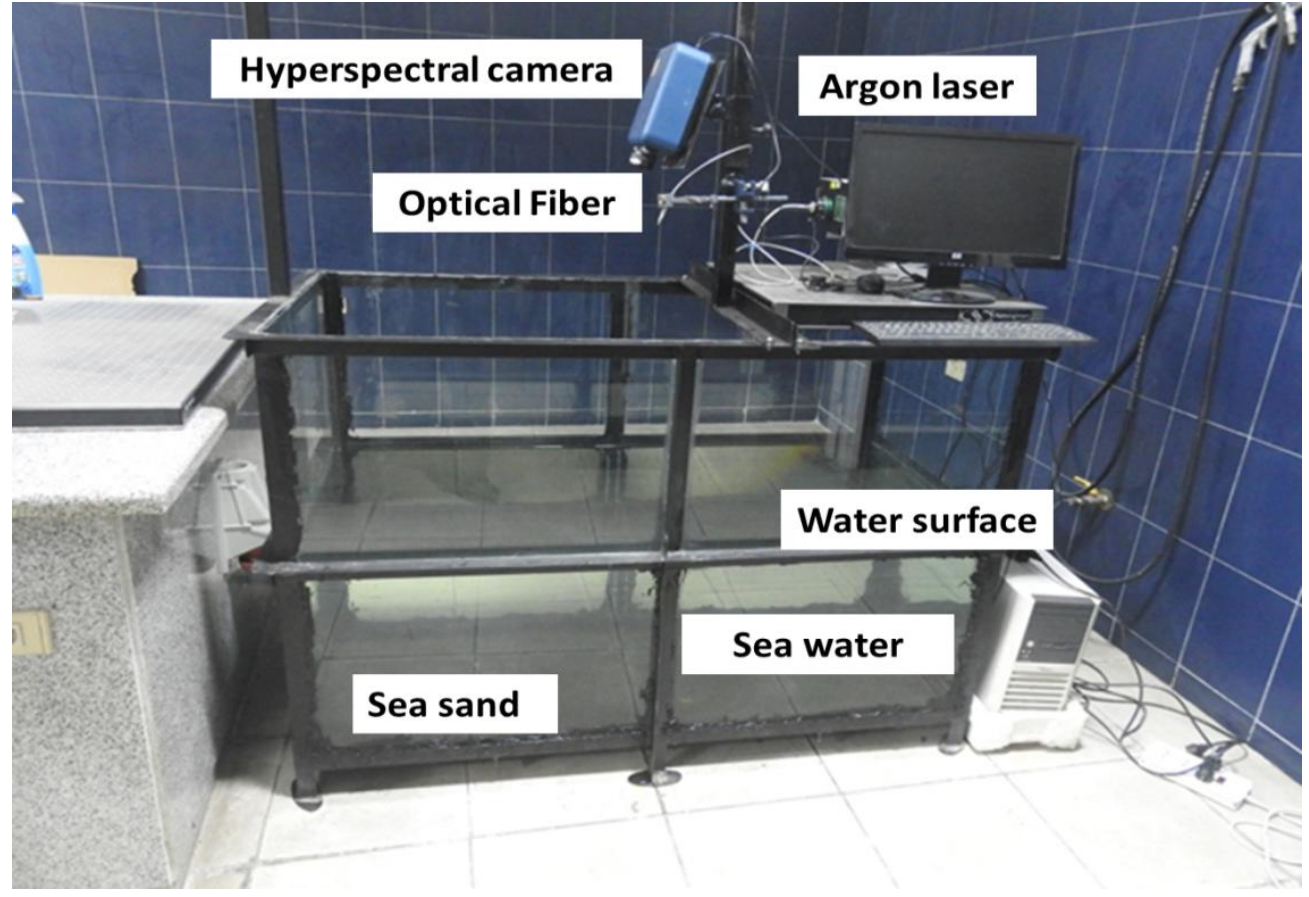

Fig.8 Experimental setup photo in off- LASER mode

\section{Setup testing:}




\section{Military Technical College \\ Kobry Elkobbah, \\ Cairo, Egypt \\ April 3-5,2018}

\section{9th International Conference \\ on Mathematics and \\ Engineering Physics (ICMEP-9)}

We use three types of scale down dummy targets having marine camouflaged targets fig.9 to simulate the detection of the underwater hostile objects in deep and shallow water. The aquarium water matches the extinction factor and turbidity of the sea water having a depth of $50 \mathrm{~m}$.

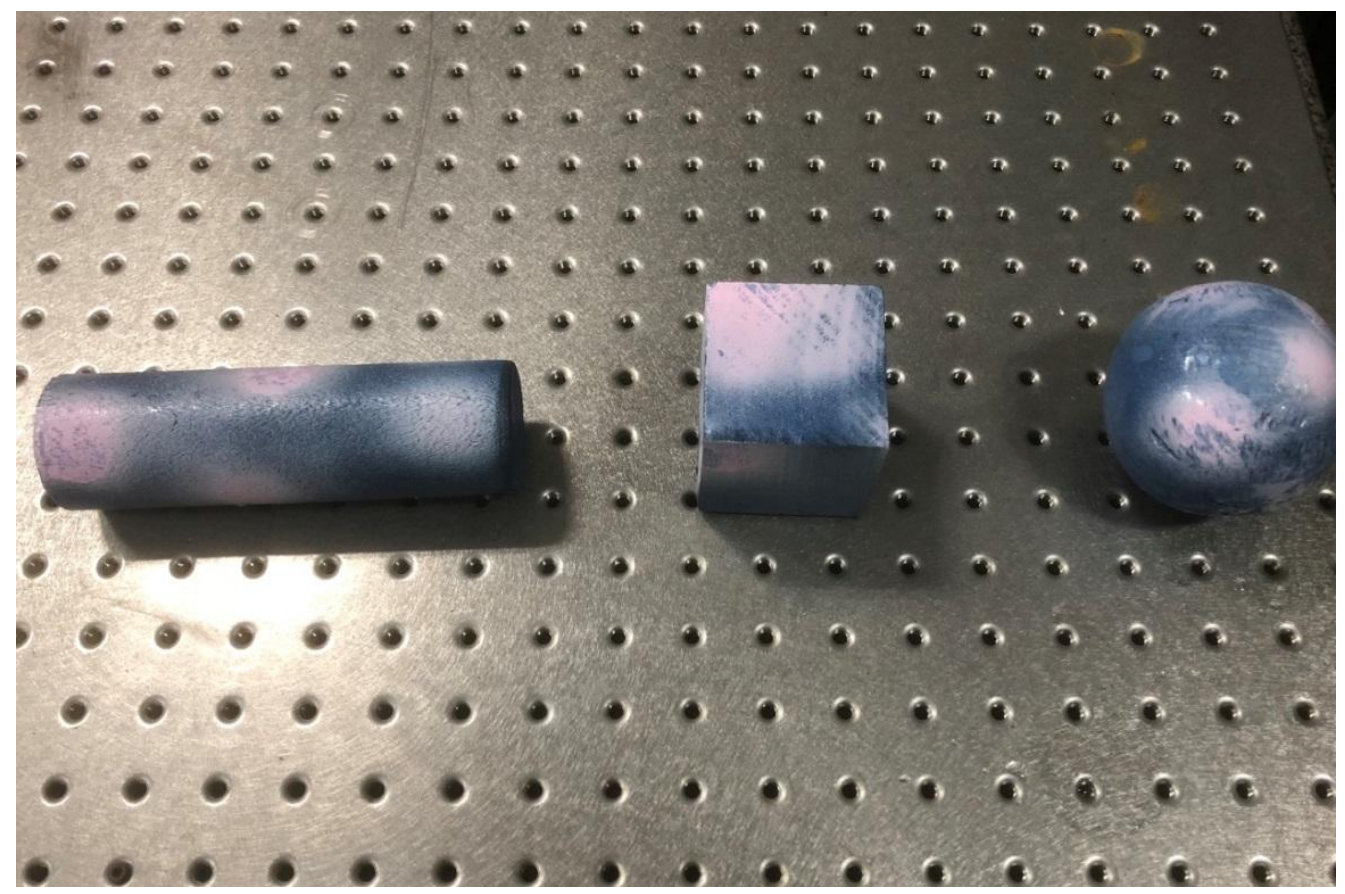

Fig.9 Different scale down camouflaged dummy targets

The dummy targets were illuminated by the Argon laser through the optical fiber terminal that took several angles of inclination simulating the airborne laser illumination of sea surface as shown in fig. 10 and fig. 11. 
Military Technical College

Kobry Elkobbah,

Cairo, Egypt

April 3-5,2018

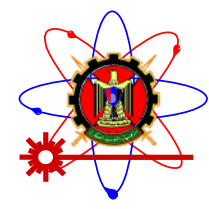

9th International Conference on Mathematics and

Engineering Physics (ICMEP-9)

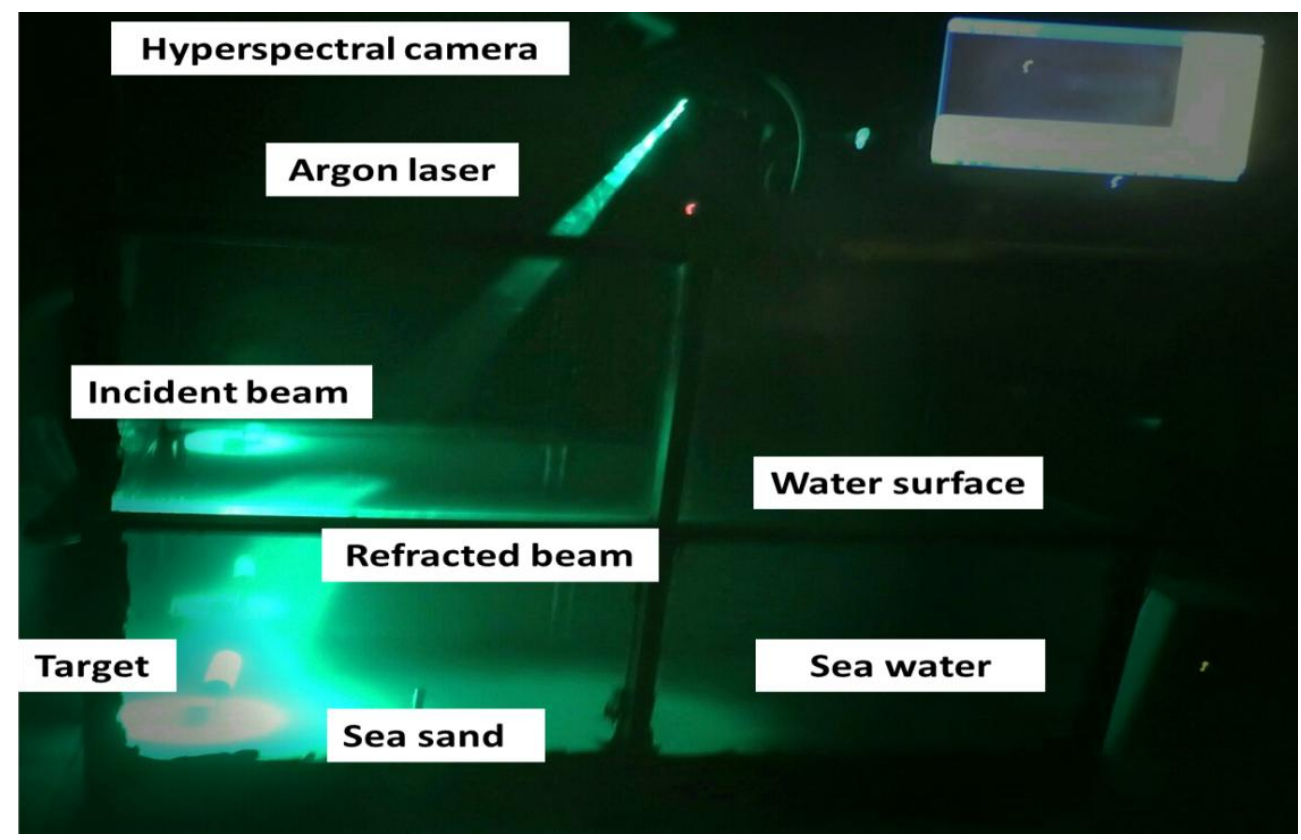

Fig. 10 underwater target illumination and detection using the designed experimental setup

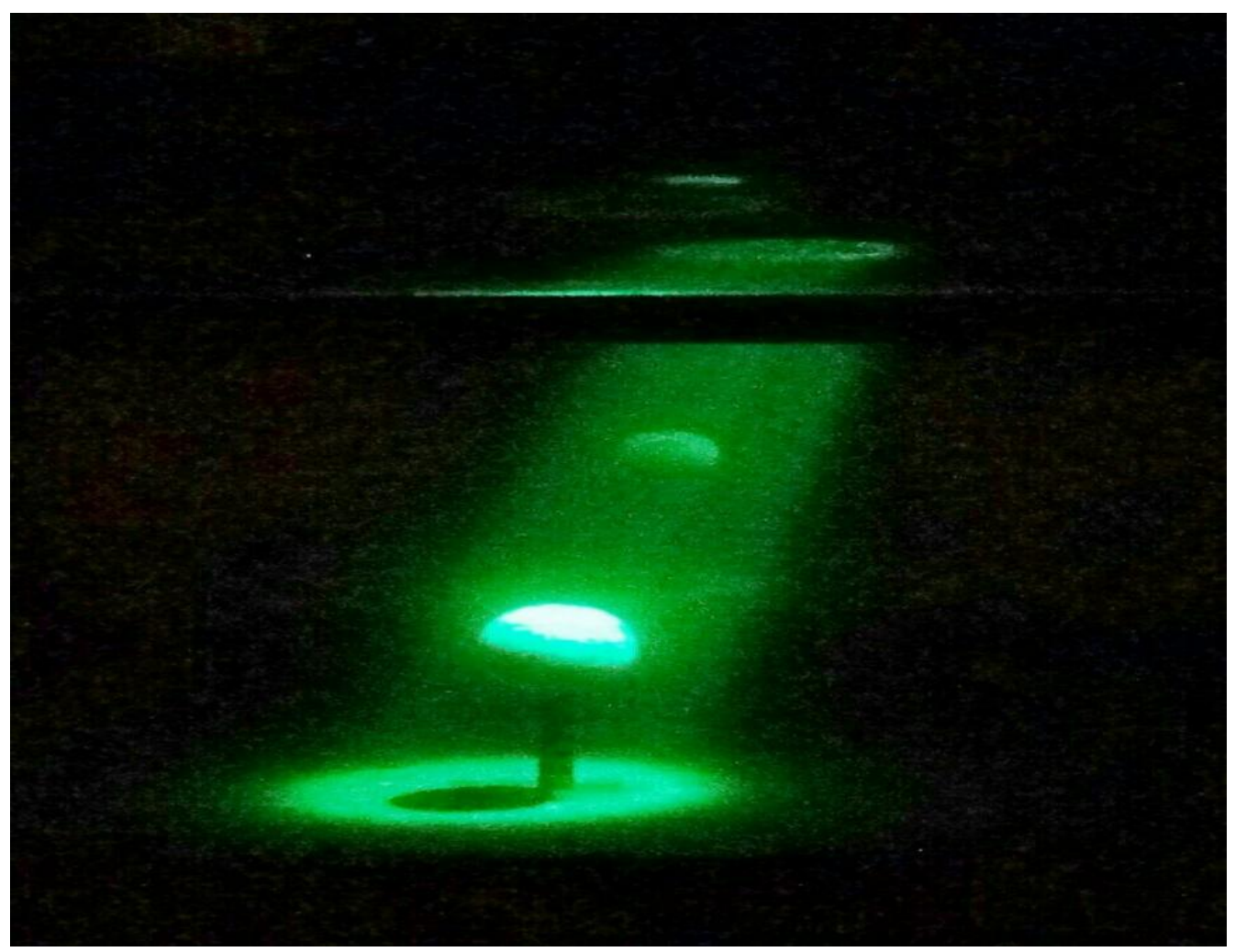

Fig. 11 underwater target illumination and detection using the designed experimental setup 
Military Technical College

Kobry Elkobbah,

Cairo, Egypt

April 3-5,2018

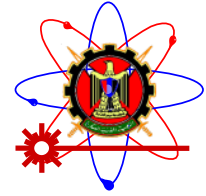

9th International Conference on Mathematics and

Engineering Physics (ICMEP-9)

The hyperspectral photography of the seam revealed several degrees of contrast as a function of wavelength. Fig. 12 illustrates the hyperspectral image of the camouflaged spherical underwater target and it is clear that the best wavelength filter used for detecting the target was that of band pass of $2 \mathrm{~nm}$ wide at wavelength of $500 \mathrm{~nm}$.

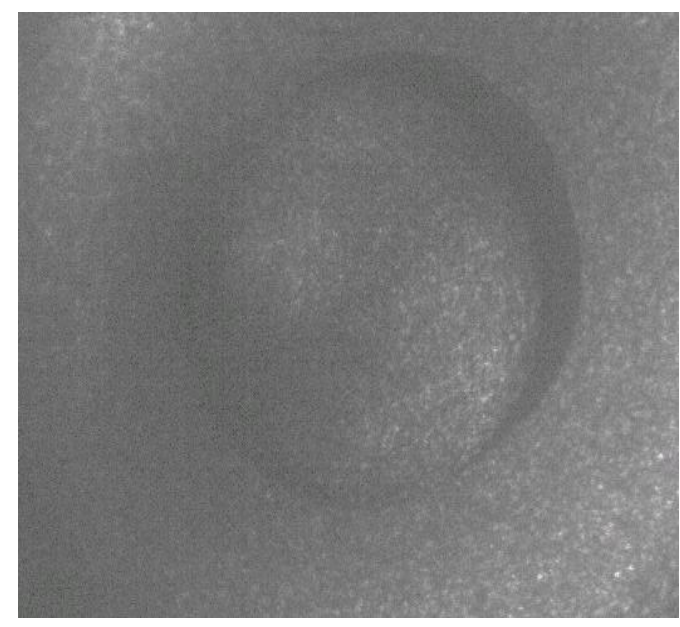

(a)Target image at $480 \mathrm{~nm}$

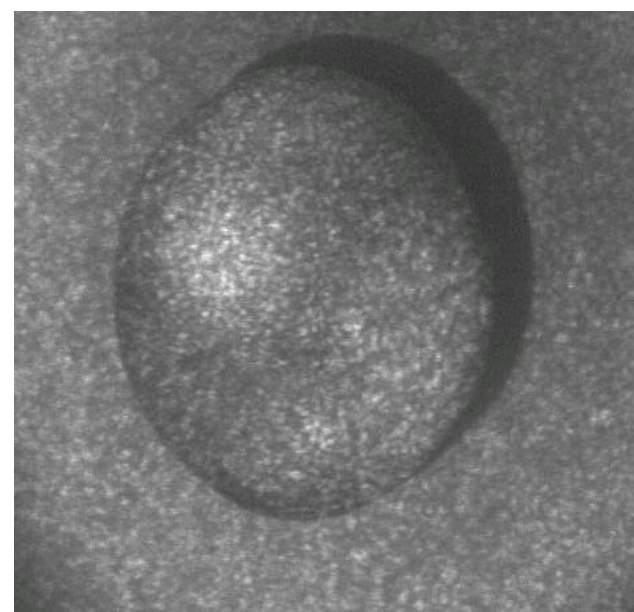

(b)Target image at 500nm

Fig. 12 hyperspectral image of the camouflaged spherical underwater target

\section{Conclusion}

The optical characteristics of the aquamarine medium can be simulated using a hyperspectral imaging test aquarium capable of distinguishing the optical image of camouflage targets at typical optical extinction and turbidity. This technique enables the selection of the best airborne illumination source wavelength that encounters camouflaged hostile targets.

A Matlab model to simulate a system to detect submerged targets in the sea water in which we analyze the transmission of light in the air and in the water based on the properties of the scattering and absorption from the sea water were established by Morel equations which give specific values of these parameters depending on the chlorophyll concentration. The data extracted from the model shows the different shape target detection and the sea surface detection.

\section{References:}


Military Technical College

Kobry Elkobbah,

Cairo, Egypt

April 3-5,2018

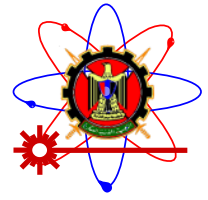

9th International Conference

on Mathematics and

Engineering Physics (ICMEP-9)

[1] Manolakis, Dimitris, and Gary Shaw. "Detection algorithms for hyperspectral imaging applications." Signal Processing Magazine, IEEE 19.1 (2002): 29-43.

[2] Heege, Thomas, Anke Bogner, and Nicole Pinnel. "Mapping of submerged aquatic vegetation with a physically based process chain." Remote Sensing. International Society for Optics and Photonics, 2004.

[3] Kutser, Tiit, Ian Miller, and David LB Jupp. "Mapping coral reef benthic substrates using hyperspectral spaceborne images and spectral libraries."Estuarine, Coastal and Shelf Science 70.3 (2006): 449-460.

[4] Jay, Sylvain, Mireille Guillaume, and Jacques Blanc-Talon. "Underwater target detection with hyperspectral data: Solutions for both known and unknown water quality." Selected Topics in Applied Earth Observations and Remote Sensing, IEEE Journal of 5.4 (2012): 1213-1221.

[5] Volent, Z., Johnsen, G., \& Sigernes, F. (2009). Microscopic hyperspectral imaging used as biooptical taxonomic tool for micro- and macroalgae. Applied Optics, 48, 4170-4176.

[6] Sakshaug, E., Johnsen, G., \& Volent, Z. (2009). Light. In E. Sakshaug, G. Johnsen \& K. Kovacs (Eds.), Ecosystem Barents Sea (pp. 117-138). Trondheim, Norway: Tapir Academic Press.

[7] Johnsen, G., Volent, Z., Sakshaug, E., Sigernes, F., \& Pettersson, L. H. (2009). Remote sensing in the Barents Sea. In E. Sakshaug, G. Johnsen \& K. Kovacs (Eds.), Ecosystem Barents Sea (pp. 139-166). Trondheim, Norway: Tapir Academic Press.

[8] Johnsen, G., Volent, Z., Dierssen, H., Pettersen, R., Van Ardelan, M., Søreide, F., Fearns, P., Ludvigsen, M., \& Moline, M. (2013). Underwater hyperspectral imagery to create biogeochemical maps of seafloor properties In J. Watson \& O. Zielinski (Eds.), Subsea optics and imaging (pp. 508535). Cambridge, UK: Woodhead Publishing.

[9] Sabins, F. F. (1999). Remote sensing for mineral exploration. Ore Geology Reviews, 14, $157-$ 183.

[10] Volent, Z., Johnsen, G., \& Sigernes, F. (2007). Kelp forest mapping by use of airborne hyperspectral imager. Journal of Applied Remote Sensing, 1(011503), 1-21.

[11] Pettersen, R. (2013). Identification of Marine Organisms using Chemotaxonomy and Hyperspectral Imaging. (Philosophiae Doctor), Norwegian University of Science and Technology, Trondheim.

[12] Pettersen, R., Johnsen, G., Bruheim, P., \& Andreassen, T. (2013). Development of hyperspectral imaging as a bio-optical taxonomic tool for pigmented marine organisms. Organisms, Diversity and Evolution, 14(2). 237-246.

[13] Mohamed Darwiesh, Ashraf F. El-Sherif, Yasser H. El-Sharkawy, Mahmoud F. Hassan, "Simulation and Characterization of Underwater Target Detection using LIDAR System", proceeding of 17 th International Conference on AEROSPACE SCIENCES \& AVIATION TECHNOLOGY Military Technical College, Cairo, Egypt. April 2017. 
Military Technical College Kobry Elkobbah,

Cairo, Egypt

April 3-5,2018

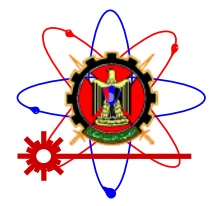

9th International Conference on Mathematics and

Engineering Physics (ICMEP-9) 